\title{
Some considerations about coastal ocean observing systems
}

\author{
by K. H. Brink ${ }^{1,2}$ and Anthony R. Kirincich ${ }^{1}$
}

\begin{abstract}
Coastal ocean observing capabilities are evolving rapidly, both in terms of sensors and in terms of the volume of information available. We discuss the aspects of the coastal ocean that make it a unique environment, both in terms of physical processes and measurement techniques. Although many global-level systems are relevant to the coastal ocean, we concentrate on treating systems that are unique to the continental shelf environment. Further, we briefly discuss examples of measurement systems that would be useful for developing and driving ocean prediction systems.
\end{abstract}

Keywords: Coastal observations, high-frequency radar, continental shelf

\section{Introduction}

The coastal ocean can be defined as including the surf zone and the continental shelf and slope. This definition encompasses a wide range of shelf environments, ranging from relatively wide, flat shelves (e.g., the North Sea, the East China Sea, or the U.S. East Coast) to narrow shelves (e.g., Peru or the U.S. West Coast), as well as shelves adjacent to western or eastern boundary currents. Although estuaries are a fascinating and important environment, they will not be considered here. Primarily because of the presence of the coastline onshore as well as the shallower bottom depths, coastal oceans have unique features not seen in open-ocean environments. This article addresses both the properties of the coastal ocean and measurement techniques particular to coastal areas that are critical to shaping the science of ocean prediction in these areas.

It is difficult to overstate both the importance of the coastal environment to modern society and the increased informational needs required to manage the rapidly expanding societal uses of this setting effectively. As just one example, many of the world's greatest fisheries are in coastal waters. Thus, management, conservation, and efficient exploitation all benefit from a better knowledge of the shelf environment. Coastal oceans are the site of numerous forms of mineral extraction, most obviously oil and gas, but also including sand, gravel, and diamonds. Thus, environmental risk assessment and emergency response both depend on reliable observations of the coastal environment. The dense populations of small commercial

1. Department of Physical Oceanography, Woods Hole Oceanographic Institution, Woods Hole, MA 02543.

2. Corresponding author:e-mail:kbrink@whoi.edu 
and recreational vessels, operating in a range of environmental conditions within the coastal ocean, require effective and efficient search and rescue operations, which are benefited by reliable predictions of the surface drift. Coastal oceans are important for a range of naval operations, so there is a growing demand for refined knowledge and prediction of waves, acoustic conditions, and other properties. The point of the preceding litany is that there are many parties with a stake in improved coastal modeling and prediction.

This breadth of motivations has led to the development of coastal ocean observation and modeling systems in a wide range of settings globally. These diverse and widespread systems are constantly changing as the drivers for measurements change and as technologies advance quickly. A good sampling of present capabilities can be found in Liu, Kerkering, and Weisberg (2015). Because of the rapidly evolving nature of the systems, we make no attempt to provide a comprehensive list of current systems or methodologies. Rather, we attempt to discuss some principles that guide system developments and provide a limited set of illustrations of developments to date. Many existing coastal ocean observing systems are confederated through the Intergovernmental Oceanographic Commission. The related website (http://imos.org.au/gra.html) provides access to regional associations and hence to actual observing systems currently in operation.

From a purely practical and operational standpoint, the coastal setting presents a number of challenges and opportunities for ocean prediction. Disparate groups of stakeholders have both similar goals and a mutual dependence on each other's contributions toward supporting coastal ocean observations and predictions but have struggled to work effectively together. Thus, the motivation for coastal ocean prediction is strong, but the field is somewhat fractured.

This article aims to explore three key questions: What makes the coastal ocean different from the larger global ocean? What tools can be used in coastal ocean environments to provide these measurements? How are these measurements currently being made in a systematic way that can support coastal ocean prediction? Some answers to these motivating questions are described subsequently, broken up into sections describing the physical setting, parameters of interest, measurement approaches, and observation systems. For the purpose of this work, an observation system is defined as a collection of measurements or measurement programs routinely made over an extended time period. Thus, the focus is on operation systems, rather than on the diversity of measurement types that are available to the specialized scientific community.

\section{Physical setting: The coastal ocean as a unique system}

Before discussing coastal observations, we consider what physical aspects of the coastal ocean set it apart from the deeper ocean. Specifically, we seek to demonstrate how these differences impose constraints that are not present in the open ocean.

The presence of a coastal boundary is critical. This boundary blocks the cross-shelf Ekman transport associated with alongshore winds, and this blockage leads to very efficient 

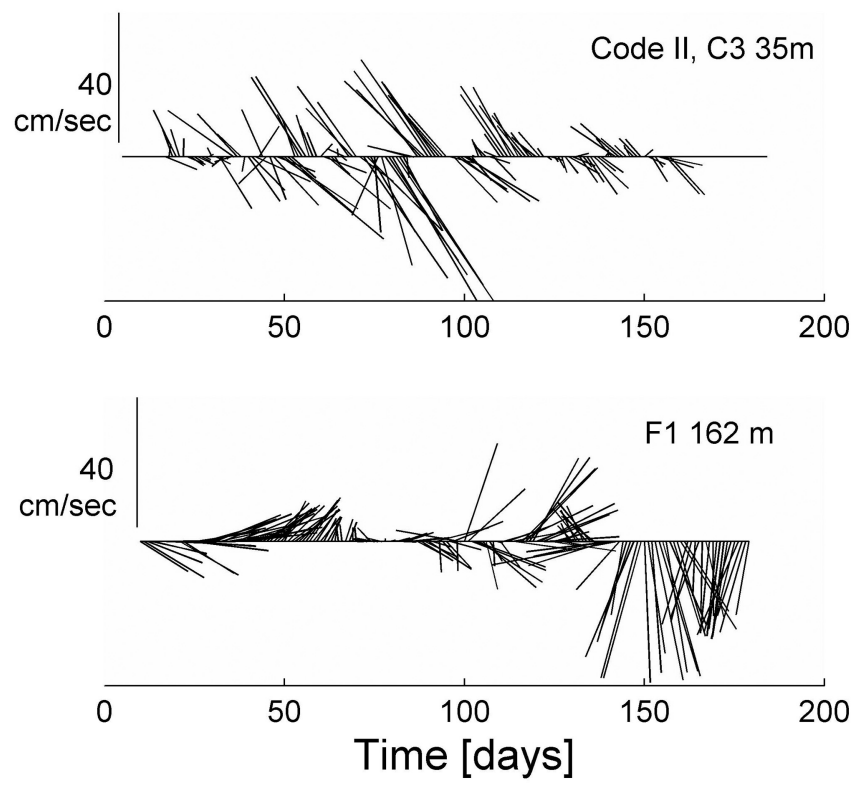

Figure 1. Vector time series of currents at a midshelf, middepth location off California (upper row: CODE (Coastal Ocean Dynamics Experiment) 2 C3 mooring, 35 m depth; e.g., Winant, Beardsley, and Davis 1987) and from a representative midocean location in the eastern North Pacific (B2 mooring at $75 \mathrm{~m}$ depth at $32^{\circ} 41^{\prime} \mathrm{N}, 128^{\circ} 2^{\prime} \mathrm{W}$; Brink 1995). Both time series have been treated with the same low-pass filter to remove tidal fluctuations. Note that the shelf time series has a clearly defined preferred orientation, which is roughly parallel to the local isobaths.

generation of shelf currents by the wind (see, e.g., Brink 1998). This efficiency means that wind-driven currents are often extremely important aspects of shelf variability. This, in turn, means that very often the dominant time scale for current variability (at least for frequencies lower than tidal) is the time scale of wind or weather events-from a few days to a couple of weeks. Similarly, currents in the surf zone and inner shelf can be driven largely by the momentum transferred onshore by surface wave propagation (e.g., Lentz et al. 1999). Surf zone variability has time scales partly determined by the weather systems that generate the waves. (These two driving agencies also mean that useful predictions of coastal ocean currents require frequent input of high-quality wind and wave data as forcing fields.) In either case, these 2- to 10-day continental shelf time scales can be contrasted with oceanic systems where the dominant time scale is often associated with mesoscale variability: 20100 days (e.g., Schmitz 1988). This contrast in time scale is readily apparent from a simple inspection of historical data from the coastal ocean (Fig. 1).

Tidal currents (e.g., Simpson 1998) are often an important part of the current variability over shelves as well. Although the tides themselves are largely generated by gravitational forces operating on basin scales, their effects are most obvious over the shelf. This happens 
for two reasons. One is simply continuity: as a tidal transport encounters the shelf and slope, it has to accelerate in order to conserve mass. More interestingly, there are often contexts, such as the Gulf of Maine/Bay of Fundy system, where tidal frequencies resonate with inertia-gravity waves over the shelf. The results can be spectacularly strong currents and sea level changes. From our perspective, tides are an important part of the variability that needs to be measured and predicted accurately as they lead to a number of interesting secondary effects that are themselves important. For example, tides can interact with sloping topography to give rise to rectified currents (e.g., Simpson 1998) and to generate internal waves ("internal tides") that propagate onto the shelf or offshore. Tidal currents, when they reach speeds of $O\left(1 \mathrm{~m} \mathrm{~s}^{-1}\right)$ lead to bottom stresses comparable to those exerted by a hurricane over land. Areas subject to these stresses are often regions of homogenized waters, such as over Georges Bank, having strong fronts that separate mixed from ambient waters. Tides, then, are an important part of the variability, but they also generate secondary effects that can be even more important than the tides themselves.

In contrast to typical midocean conditions, coastal currents are decidedly anisotropic at time scales of a day or longer all across the shelf, (e.g., Kundu and Allen 1976; Lentz and Fewings 2012; see Fig. 1): alongshore currents are typically much stronger than crossshelf currents. Very close to shore, this dominance of alongshore currents over cross-shelf currents is simply a boundary constraint: because flow cannot cross the coastline, it is increasingly constrained to parallel the boundary as it becomes closer. Over the continental shelf and slope, where Earth's rotation is of dominant importance on time scales longer than a couple of days or so, flow is not allowed to cross isobaths unless mitigating effects associated with time dependence, mixing, or nonlinearity come into play. Thus, alongshore currents are relatively (compared with cross-shelf currents) easy to measure and predict. However, for many processes that are biologically or societally important, such as coastal upwelling or contaminant dispersal, it is the weaker cross-shelf current that is actually the more important component because cross-shelf nutrient or dissolved material gradients are generally stronger than alongshore.

The importance of the cross-shelf current raises all sorts of interesting complications. First off, being weak, it is hard to measure with certainty in the presence of dominating alongshore current availability. For example, if a small error, say $O\left(1^{\circ}-2^{\circ}\right)$, is made in defining the alongshore direction, it will have no substantial effect on the alongshore currents, but it could lead to contamination of cross-shelf current observations by alongshore currents (as the sine of a small number times a large current can be comparable to that smaller, cross-shelf current). The problem is further complicated because alongshore currents typically have large spatial correlation scales (comparable to those of the wind forcing), whereas crossshelf currents typically have correlation scales of $10 \mathrm{~km}$ or less (e.g., Kundu and Allen 1976; Dever 1997). It seems likely (Brink 1987) that this spatial scale discrepancy is associated with different aspects of the flow field dominating: wind driving for alongshore flow, and small-scale eddies for cross-shelf flows outside the surface or bottom boundary layers. This eddy scale would presumably be around the internal Rossby radius of deformation, 
or around $5 \mathrm{~km}$ over midlatitude shelves (K. H. Brink and H. Seo, 2016). If indeed the crossshelf flow is dominated by different, smaller-scale physics than what drives the alongshore flow, the measurement and prediction problem, at least from a deterministic standpoint, becomes very difficult.

The coastal ocean, obviously, lies near the land, and so it is the place where fresh or brackish runoff from land enters the ocean. This means that buoyancy forcing is often dominant on scales ranging from a nearshore fringe out to the shelf width or greater (e.g., Hill 1998). These freshwater outflows are often bounded by a front, and they often have practical importance because the outflow contains contaminants or excess nutrients carried down from rivers. The integrity or dispersal of the freshwater outflow then determines whether damaging effects such as eutrophication (e.g., Rabalais 2005) are concentrated locally or dispersed. Adequate prediction of these buoyancy-driven currents requires knowledge of the estuarine outflows, and it requires a good capability for predicting turbulent mixing both over the shelf and within the relevant estuaries. Needless to say, the importance of runoff from land means that salinity variations are often substantial over the shelf, and that they need to be measured and modeled adequately in order to obtain predictability.

In some situations, the coastal requirements for absolute measurement accuracy differ from those in the open ocean. For example, abyssal ocean measurements that are to be used for evaluating deep currents for ocean heat content may call for an accuracy of $0.01{ }^{\circ} \mathrm{C}$ or better, whereas it is hard to imagine any coastal application where this sort of accuracy would be necessary. Although true for measurements of absolute temperature, salinity, and so forth, other aspects such as the surface mixed-layer depth and chlorophyll or nutrient contents require the same accuracy as other parts of the ocean.

The coastal ocean is often the site of a variety of types of fronts. These fronts can be associated with wind-driven upwelling (e.g., Austin and Barth 2002), estuarine outflow (e.g., Hill 1998), tidal mixing (e.g., Simpson 1998), oceanic western boundary currents (e.g., Glenn and Ebbesmeyer 1994), or the juncture of fresher shelf and saltier ocean waters (e.g., Linder and Gawarkiewicz 1998). In each of these cases, the fronts are at least sometimes associated with strong current shears and hydrodynamic instabilities. These instabilities represent smaller-scale (5-20 km perhaps) variations in along-shelf currents that present their own challenges in terms of deterministic modeling and observation.

The coastal ocean is very accessible compared with the open ocean. Thus, much of it can be reached conveniently from land within a day by ship or minutes by aircraft. Autonomous underwater vehicles (AUVs) and gliders can be deployed easily from a small boat and yet be near the area to be sampled. Close to land, simple, economical telemetry systems using cell phone technology, for example, become feasible. Shore-based remote-sensing systems are also a real possibility and are becoming increasingly widespread. Various ships and platforms of opportunity exist and can also be used to access the ocean economically. Thus, simply the nearness to land at least partially compensates for the many difficulties imposed by the coastal ocean's short space and time scales. 
The previous factors require that the design of any robust coastal ocean observing system has unique constraints that will vary from region to region depending both on the required data products and on regional characteristics. For example, the importance of river inputs or sea ice would lead to vastly different sampling schemes and equipment choices. Given these considerations, it is clear that designing a system calls for careful, case-by-case attention. In this regard, numerical model observing system simulation experiments (OSSEs: e.g., Robinson, Lermusiaux, and Sloan 1998; Aydoğdu et al. 2016) are a valuable tool as careful thought must be given to ensure operational predictive models will be given adequate ocean input and verification data.

\section{Parameters of interest}

Successful modeling and prediction require a basic level of understanding of the relevant dynamics. From a physical standpoint, this might simply consist of knowing what commonly used approximations are appropriate for desired prediction. For nonphysical systems (e.g., ecosystem prediction), the underlying dynamics are less well formulated, and so basic understanding, in addition to routine modeling and observation, can be a primary motivation for measurements. Once the appropriate dynamics are defined, there is still a need to define the critical variables and the sampling requirements. For example, as in the open ocean, temperature and salinity, which determine the density structure of the coastal ocean and thus help determine the geostrophic component of currents, are fundamentally important variables to measure. For modeling purposes, the vertical structures of hydrography and currents are critically important over the shelf. For example, ageostrophic currents associated with winds and bottom friction are found in deep and shallow boundary layers that occupy a substantial portion of the water column. Beyond these and other water column variables, successful modeling requires knowledge of boundary forcings such as wind stress, freshwater inflow, and lateral fluxes at open boundaries.

Knowledge of the spatial correlation scales of water column variables in coastal settings is critical to using observations with a predictive model and to understanding the quality of model forecasts/predictions. Spatial scales need to be known in order to do optimal interpolations or to determine the amount of independent data for statistical evaluation. This is an acute issue in the coastal ocean as the scales of variability can be so small, as described previously. When temperature, salinity, or currents are measured at a fixed point in space by a mooring or floating platform, it is straightforward to calculate time scales, but estimation of spatial scales would require time series from several locations. However, newer land-based remote-sensing platforms such as high-frequency (HF) radar (e.g., Glenn and Schofield 2009) enable more direct estimations of velocity spatial scales. In any case, it is important to understand the natural space, time, and propagation speed scales for variables of interest and to use this information in designing an observation system and in evaluating model outputs (Arnold and Dey 1986; Malone and Cole 2000). 
Direct observations of biologically important parameters are becoming necessary as predictive models of the coastal ocean attempt to forecast changes in ecological systems. Assimilative physical models constrained by temperature and salinity often employ variations in vertical mixing or forcing conditions to adjust the model result toward the observations (e.g., Goebel et al. 2010). Although this approach can work nicely for the limited number of variables in a physical system, added variables, such as a dissolved nutrient concentration, can lead to problems. This follows because a mixing rate that is artificially revised to give suitable results for, say, temperature, may degrade the prediction of some other variable that is not used as an initial constraint.

In any case, accurate hindcasts and forecasts of biological variables require useful measurements (or proxy measurements) for nutrient concentrations, plankton populations, dissolved oxygen, growth rates, and so forth. Thus, not only are there more variables that need to be measured, but they are also relatively difficult quantities to measure. Although relevant sensor systems are improving rapidly (e.g., Moore et al. 2009) and increasingly sophisticated efforts are being made (e.g., Banas et al. 2009), we still have a long way to go before the requisite quality, consistent calibrations, and absolute accuracy can be regularly obtained on appropriate space and time scales. The problem is made more difficult when sampling scales are considered: there is evidence (e.g., Brink et al. 2007; Schaeffer et al. 2016) that correlation length scales for chlorophyll (a dynamically passive tracer) are shorter than those for temperature over the shelf. Further, these scales vary in the vertical (Fig. 2). This implies that adequately refined sampling for temperature could be inadequate for chlorophyll. How general this scale discrepancy might be is unknown, but it is consistent with the notion that passive tracers in an eddy field tend to get stretched out to very small scales (e.g., Haidvogel and Keffer 1984).

\section{Sensors and measurement systems}

A comprehensive account of the observational capabilities, both platforms and sensors, relevant to coastal ocean prediction could easily fill an entire volume, especially if one accounts for the remarkable, rapidly evolving suite of nonphysical measurements. A list of platforms might include gliders, ships of opportunity, moorings, or expendable probes. Novel sensors include optically based systems, acoustical measurements, and systems using wet chemistry. A sampling of sensors and approaches can be found, for example, in the recent volume edited by Liu, Kerkering, and Weisberg (2015). As many aspects of observation-prediction systems are covered elsewhere, the present article concentrates on observing systems that are unique to the coastal ocean and those aspects of globally relevant systems that are useful to the coastal ocean. This approach admittedly underrepresents some key areas, but it is hoped that the present discussion at least illuminates issues that are relevant to a broader range of observations, thus serving all areas of coastal oceanography. 


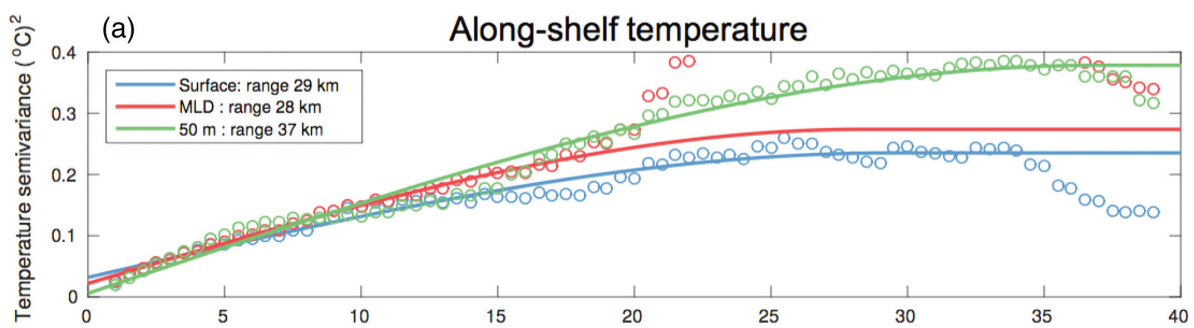

(b)

Along-shelf salinity
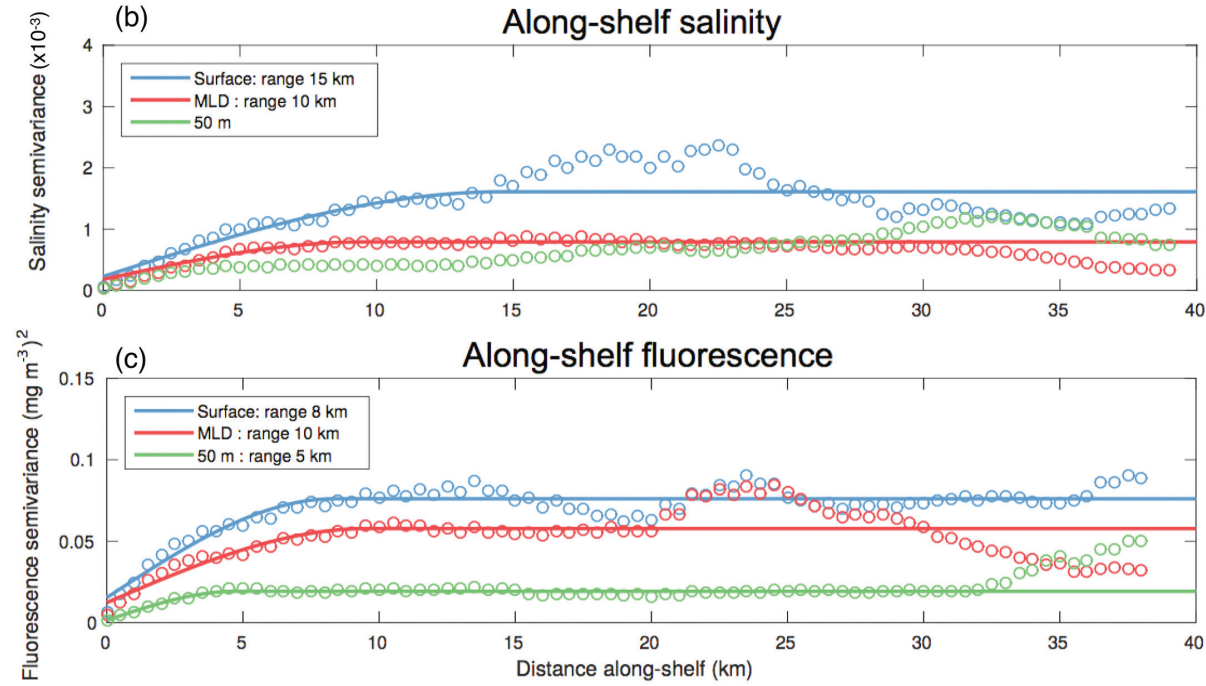

Figure 2. Semivariograms (structure functions) of temperature (a), salinity (b), and fluorescence (c) versus alongshore separation from measurements made off the eastern coast of Australia. Colors correspond to surface values (blue), mixed-layer values (red), and $50 \mathrm{~m}$ observations (green). The structure function is equivalent to variance times (1 minus autocorrelation). Thus, where the curves flatten out, the correlation is roughly zero. The larger the distance over which it takes the curve to flatten out, the longer the correlation scale. After Schaeffer et al. (2016).

\section{a. Relevant global observations}

$i$. Satellite altimetry in the coastal ocean. Global altimetry can add greatly to observational systems in coastal waters. Studies using satellite altimetry in coastal regions (e.g., Strub and James 2000; Chaigneau, Eldin, and Dewitte 2009; Strub et al. 2015) have documented seasonal cycles and mesoscale variability of areas adjacent to coastal zones. However, several issues significantly impact the altimeter's usefulness as the coastline is approached. First, large amounts of altimetry data are lost in the vicinity of land (0-40 km offshore; Castelao and He 2013) when using processing methods and calibrations appropriate for open-ocean environments (Chelton et al. 2001). Second, temporal repeat times for altimetry satellites are long (10-14 days) relative to time scales of the wind events (a few days) that 
often dominate current variability in the coastal ocean. In addition, it is important to have good tidal estimates (if only to remove the dominating tidal variability) and accurate bottom topographic information. Thus, previous efforts have often, especially when the shelf is narrow, used altimetry solely for characterizing low-frequency variability offshore of the shelf break.

Little can be done regarding long temporal repeat times, apart from launching additional altimeters with different orbital sampling, but significant progress has been made on the issue of resolution and errors near the shoreline. Altimeters can suffer from errors because of inaccuracies in the wet tropospheric correction, land contamination, and tracking uncertainties-all of which are accentuated closer to the coast. Accounting for these sources of error with enhanced algorithms allows for custom-processed coastal altimetry data sets that can now extend to within $10 \mathrm{~km}$ of the coast (Vignudelli et al. 2011; Pascual et al. 2015) with reasonable uncertainties provided that sufficient signal is present (Vignudelli et al. 2005). Thus, satellite altimetry is a potentially important coastal data set, especially when other means are not available for measuring variability in remote locations. However, the temporal sampling issues remain a drawback for this data source in the coastal ocean.

ii. Satellite chlorophyll and sea surface temperature. In contrast to altimetry, space-based sea surface temperature (SST) and ocean color (hence chlorophyll) have a long history of use in the coastal ocean. Used together or with additional sensors such as HF radar, winds, and so forth, satellite SSTs and chlorophyll can be used for a wide array of applications in the coastal oceans. Representative studies include understanding the coupling of coastal SSTs with wind stress (Chelton, Schlax, and Samelson 2007), approximating nutrient fluxes into sensitive coastal areas (e.g., Beman, Arrigo, and Matson 2005), or estimating fluxes of heat across the inner part of the continental shelf (Kirincich, de Paolo, and Terrill 2012). Access to daily or higher-frequency estimates on spatial scales as small as $1 \mathrm{~km}$ make both SST and chlorophyll an immensely useful data product for coastal studies.

In the coastal ocean, potential issues arise with calibrating estimates of chlorophyll based on ocean color. Considerable effort has been put into understanding the potential of SeaWiFS or MODIS types of ocean color sensors for chlorophyll in turbid coastal waters (i.e., type 2 waters; Dall'Olmo et al. 2005). A number of types of adjustments to the algorithms successfully used in open-ocean conditions have been investigated (i.e., Beman, Arrigo, and Matson 2005; Gitelson et al. 2008; Hu et al. 2010); however, regional-specific solutions are generally needed for increased accuracy. More recent work has utilized hyperspectral imagers to provide more robust estimates of chlorophyll in turbid coastal waters (Moses et al. 2012) via airborne sensors with the hope of a transition to satellite missions.

Further, considerable errors can arise because of problems with land masking, cloud removal, and georectifying. High-resolution examinations or assimilation of coastal features are more obviously affected by masking or georectifying errors than open-ocean studies, both because the scales of interest are potentially smaller and the sharp contrast between land and ocean provides a ready metric to identify errors that might otherwise go 
undetected. A number of efforts in other science areas have addressed the errors in projecting imagery onto geographic coordinates (Kaufmann et al. 2000; Khlopenkov and Trishchenko 2008), and currently available processing algorithms should help eliminate errors masking or georectifying (Yang and Di 2004). However, recent studies of small-scale variability in complex coastal zones have rejected as much as $20 \%$ of the publicly available SST data because of erroneous or questionable georectifying (Connolly and Lentz 2014). Thus, the issue is apparently not yet resolved routinely at the scales potentially important to smallscale coastal applications.

iii. Meteorological and wave buoys. Meteorological and/or wave buoys are generally quite similar to those found offshore, potentially providing long time series of point measurements to compare with or assimilate. For a range of practical reasons, the density of high-quality meteorological moorings is much higher in the coastal ocean than farther offshore. Two important coastal aspects deserve mention, however. First, the natural spatial scales are sometimes short, $O(10 \mathrm{~km}$ ), in the coastal ocean (e.g., Winant et al. 1988), such that actual surface winds, for example, may have low correlations with other observations nearby or with results from models that are not sufficiently well resolved. Second, coastal buoy locations are increasingly being set by stakeholders with diverse motivations (e.g., water quality, storm and inundation modeling, wind resource data collection) that do not include predictive modeling of shelf currents. In addition, sensor reliability, sampling strategies, and data quality might not be optimal from the standpoint of driving predictive models.

iv. Summary. Many of the ongoing observations in the coastal ocean use the same technologies as offshore, but the sampling demands can be vastly different. For example, the shorter space and time scales typical of the shelves place more stringent demands on spatial resolution and synoptic sampling rate. Similarly, the pronounced coastal anisotropy needs to be addressed in processing continental shelf data sets (e.g., Dever 2004). Such is the case with the national archives of HF radar data, described in detail subsequently, which rely on optimal interpolation or open modal analysis (e.g., Kaplan and Lekien 2007) to extrapolate to the coastline, or fill small gaps, in sensible ways.

\section{b. Coastal-focused only}

i. Tide ganges. Useful coastal tide gauge records go back as much as 150 years in some locations (e.g., Stammer et al. 2013). Not surprisingly, these records reflect different physical processes in different frequency bands. For time scales of about a day or less, sea level variability is generally dominated by tides (e.g., Parker 1991). Given a long enough record, tidal sea level fluctuations are readily isolated from other forms of variability because the relevant frequencies are known precisely. At time scales shorter than about a day or once tides are removed, energetic signals include storm surges (which are readily correlated with winds; e.g., Murty 1984) and tsunamis (which are clearly tied to geophysical or geological 
events; e.g., Bernard and Robinson 2009). In addition, seiches can be driven by small-scale meteorologic patterns or by oceanic internal waves (e.g., Sallenger et al. 1995; Giese et al. 1998, respectively). A global capability to observe and predict geophysical tsunamis is presently in advanced stages of development (Bernard and Robinson 2009). This system involves open-ocean measurements of anomalous sea surface displacement and real-time integration of observations with wave and inundation models.

For time scales longer than roughly diurnal out to tens of days, coastal sea level provides an excellent proxy for alongshore currents over the shelf. On these time scales, it is best to adjust the measured sea level, $\zeta$, first by adding in the local atmosphere pressure, $p_{\text {atm }}$, in order to estimate the actual pressure felt by the upper oceanic water column:

$$
\bar{\zeta}=\zeta+p_{\text {atm }} /\left(g \rho_{0}\right),
$$

where $g$ is the acceleration attributable to gravity and $\rho_{0}$ is the density of seawater. The resulting quantity is generally called the "adjusted sea level", $\bar{\zeta}$, or it can be expressed in terms of a "synthetic subsurface pressure," $\rho_{0} g \bar{\xi}$. This adjustment is often called an "inverse barometer" correction, but this is not good terminology because there is no need to assume that the sea level changes by an amount that exactly cancels the atmospheric pressure change. Coastal adjusted sea level is a good proxy to alongshore currents over the shelf in this frequency range because this flow component is generally in geostrophic balance on these time scales (e.g., Brown, Irish, and Winant 1987). Further, in the weather band, there tends to be a minimum in ocean pressure variance near the shelf edge, so that the cross-shelf free surface height gradient is well estimated by

$$
\frac{\partial \bar{\zeta}}{\partial x} \approx \frac{\left(\bar{\zeta}_{\mathrm{C}}-\bar{\zeta}_{\mathrm{SE}}\right)}{L} \approx \frac{\bar{\zeta}}{L},
$$

where $x$ is the local cross-shelf coordinate, $L$ is the width of the continental shelf, and $\bar{\zeta}_{\mathrm{C}}$ and $\bar{\zeta}_{\mathrm{SE}}$ are the adjusted sea level perturbation at the coast and at the shelf edge, respectively. In practice, combining approximation (2) with a geostrophic assumption leads to surprisingly good estimates of alongshore currents at midshelf (e.g., Smith 1974).

At periods longer than perhaps 50 days, adjusted sea level is less obviously a good proxy for flow over the shelf because, on these time scales, the shelf edge is no longer a node. Some variability at seasonal time scales is associated with the expansion and contraction of seawater associated with seasonal temperature changes on broad spatial scales (e.g., Spillane, Enfield, and Allen 1987). Further, there is a good deal of evidence that, at least off the west coast of continents (eastern shore of an ocean basin), interannual variability is associated with relatively uniform pressure across the shelf, and the associated flow field extends well beyond the continental margin (e.g., Chelton, Bernal, and McGowan 1982; Clarke and Van Gorder 1994). That is to say that one does not find a pressure variance minimum at the shelf edge in this range. Along the eastern shore of a continent, there is evidence that the interannual variations in coastal sea level are associated with the integrated 
response to wind stress curl over the adjoining open ocean (e.g., Hong, Sturgis, and Clarke 2000). Thus, although coastal sea level records are always a valid and relatively easily obtained input for predictive models, their physical interpretation varies from one frequency range to another.

ii. Freshwater discharge. In many continental shelf settings, freshwater inflows from land play a critical role in establishing shelf circulation and water mass distributions (e.g., Hill 1998). From the standpoint of physical modeling, freshwater discharge is an important forcing agent. However, for many applications, what is actually contained in the water, such as dissolved nutrient concentrations or other contaminants, is also an important quantity to model and predict. Thus, it is often critical to know the volume of water flowing from riverine sources, the temperature and salinity of the water as it enters the shelf from the estuary, and its contents in terms of dissolved or suspended material.

Several steps are involved. First is gathering stream-gauging information about river volume transports. In densely populated, wealthy countries, this information is plentiful and readily accessible. However, in less densely populated areas (such as along the Gulf of Alaska) or in less wealthy countries, a smaller fraction of streams are properly gauged, and so using simplified hydrologic models (accounting for precipitation over a known basin size) can provide crude estimates that are most useful when heavily smoothed in time (e.g., Dobbins et al. 2009). Fortunately, there is some expectation that, in the future, larger rivers could be monitored with highly resolved altimeter measurements (Alsdorf et al. 2007), but this approach will likely not be useful for streams narrower than $O(100 \mathrm{~m})$. Additional information, such as temperature or dissolved nutrient content load, is harder to come by. Once the runoff reaches an estuary, it typically undergoes substantial water mass transformation (e.g., Geyer and MacCready 2014), so that a greater flux of somewhat salty water exits the estuary. Modeling processes within the estuary is nontrivial and requires substantial computing resources to be done properly. Alternatively, it is conceivable that useful information can be obtained by moorings that monitor the transport and water mass properties of flow from or near an estuary, but, to our knowledge, the effectiveness of this approach has not been carefully evaluated.

iii. HF radar. Land-based HF coastal radar systems produce time series of maps of surface currents spanning the entire shelf at useful time and space scales (Paduan and Washburn 2013). As they offer a unique view of the coastal ocean, the sampling methods, analysis techniques, and potential issues are described here in more detail than for other measurement systems. HF radars exploit the scattering of 5-25 MHz radio waves by ocean surface waves to obtain estimates of surface currents. Specifically, there is a resonant (Bragg) reflection of surface gravity waves at a known (given the radio frequency) wavelength. The Doppler shifting of this signal gives a measure of the surface gravity wave's phase speed, and the deviation of this speed from linear wave theory allows an estimate of the velocity component directed toward the radar (Stewart and Joy 1974; Paduan and Graber 1997). Radar returns 


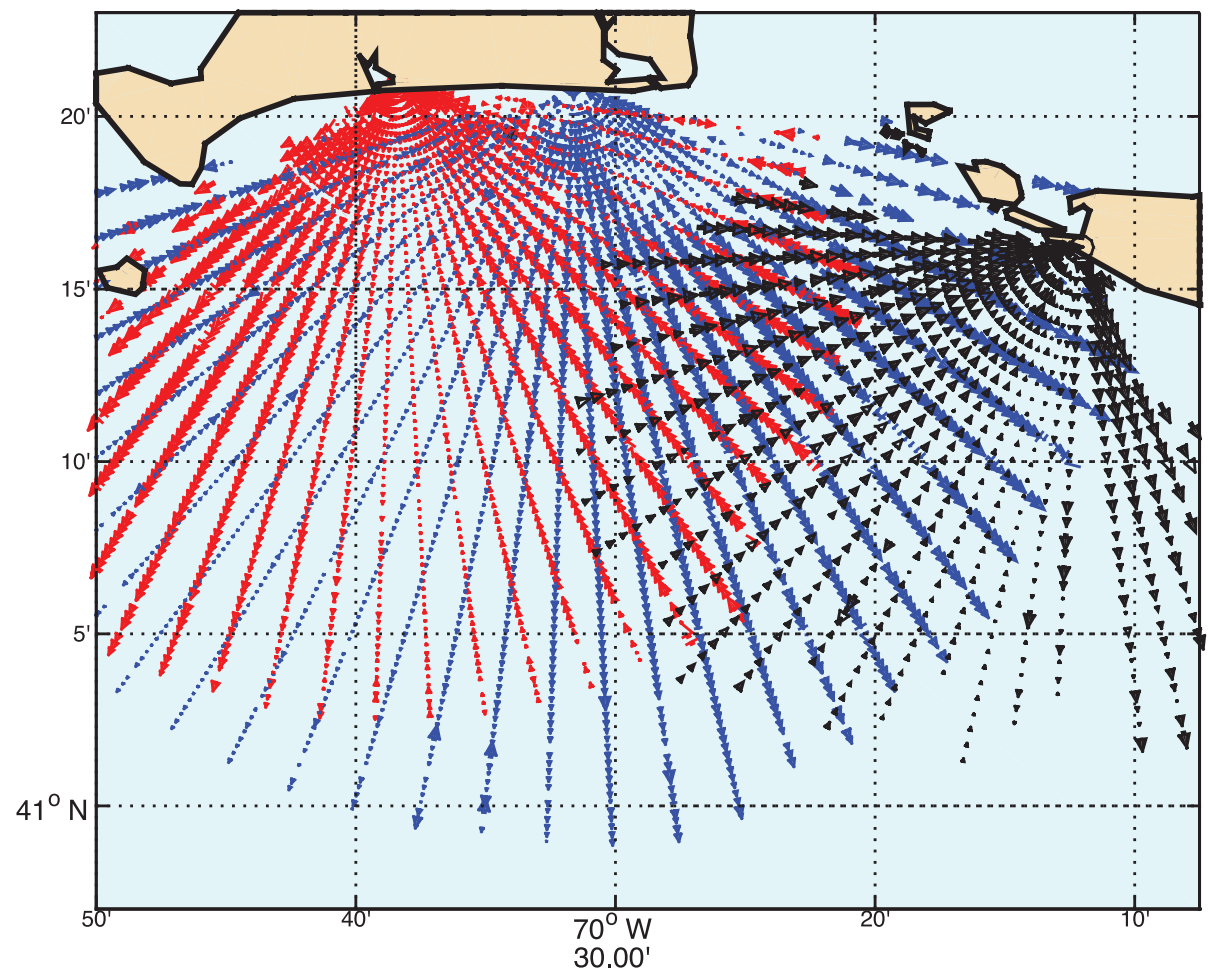

Figure 3. Example of radial velocities measured by three overlapping high-frequency radar systems deployed on the islands of Martha's Vineyard and Nantucket, Massachusetts.

from the same patch of water using two spatially separated radars enable estimation of the vector current (Fig. 3). The resulting currents represent an effective depth of 0.25 to $2 \mathrm{~m}$, depending on both the radar frequency — deeper for lower frequencies—and the near-surface vertical shear of the current (Laws 2001).

HF coastal ocean radars can be broadly grouped into two classes: direction-finding (DF) and phased array (PA) systems. PA systems utilize relatively large multiantenna arrays from which narrow beams can be formed by a spatial Fourier transform across the array. These systems measure the narrow-beam radar backscatter from the surface. DF systems utilize a compact crossed-dipole antenna with a wide beam pattern and software-based algorithms to back out the azimuthal bearings of received signals. Due primarily to their compact size, most operational radars are DF systems.

For both systems, the resolution and range of radar systems depend on the operating frequency. Although $5 \mathrm{MHz}$ systems generally have spatial resolutions of about $6 \mathrm{~km}$ and ranges of $150 \mathrm{~km}$ or more, $25 \mathrm{MHz}$ systems have resolutions and ranges of $1 \mathrm{~km}$ and 40 $50 \mathrm{~km}$, respectively. Typical radars report results on time intervals of $0.25-1$ hour, again 
depending on operating frequencies. Estimates of velocity accuracy vary widely (Emery et al. 2004; Ullman and Codiga 2004; Kohut et al. 2006; Paduan et al. 2006), but it appears, based on very careful analysis, that perhaps $6 \mathrm{~cm} \mathrm{~s}^{-1}$, as a root mean square difference relative to in situ ADCP (Acoustic Doppler Current Profiler) near-surface current estimates, might be a realistic minimum with current capabilities (Ohlmann et al. 2007; Kirincich, de Paolo, and Terrill 2012).

$\mathrm{HF}$ radar systems have reached a point where they are routinely employed to monitor coastal circulation around highly populated areas (e.g., Harlan et al. 2010). Most of these systems operate at lower frequencies, so that they generally provide spatial resolution of 5-6 $\mathrm{km}$. Although radars are often locally owned and operated by research institutions, radar systems are coordinated and partially funded by national governments. The motivation for these measurements is operational: drivers include oil spill monitoring, search and rescue, and efficient shipping. To that end, in the United States, a number of operational products are routinely produced by National Oceanic and Atmospheric Administration (NOAA)supported operators, including a Short Time Prediction System (Ullman et al. 2006) used by the U.S. Coast Guard for search and rescue and input data structures for NOAA's GNOME (General NOAA Operational Modeling Environment) oil spill prediction model.

A number of studies have examined the potential gains in coastal ocean model accuracy via assimilation of HF radar surface current observations (Oke et al. 2002; Kurapov et al. 2003, 2009; Oke, Sakov, and Schulz 2009; Zhang, Wilkin, and Arango 2010). Using the HF radar data for assimilation in models does call for some special attention because of the vertical confinement of the information (e.g., Oke et al. 2002), but the methodology is now well in hand. Some operational-mode models now routinely assimilate radar-based velocity data (e.g., Zavala-Garay, Wilkin, and Levin 2014), and this practice will probably soon be widespread.

Radar-based surface current observations have been readily combined with data from other remote-sensing platforms or methodologies to examine the coastal ocean in entirely new ways. Because of the two-dimensional velocity fields that result from HF radar observations, the results are ideally suited for use in understanding coastal circulation and exchange using Lagrangian coherent structures (LCS). Work by Shadden et al. (2009) and Olascoaga et al. (2006) illustrated the utility of LCS calculations to define barriers to exchange in the coastal zone and their potential effects on the transfer of pollutants or biological organisms. Kim et al. (2011) recently examined the along-shelf wave number spectra of surface currents possible from the large number of radars along the U.S. West Coast, illustrating that the HF radar observations excelled at producing viable estimates of wave number and frequency spectra of along-shelf velocities, particularly at the important smaller scales where the satellite products become noisy. Finally, recent work by Kirincich et al. (2013) using high-resolution radar systems illustrated that HF radar-based currents, paired with AVHRR (Advanced Very High Resolution Radiometer) SST imagery, can observe the spatial structure of complex quantities such as advective heat fluxes at small $(1 \mathrm{~km})$ scales within the coastal ocean. 
In addition to providing estimates of surface currents, HF radars have the potential to provide remote estimates of the surface wind and wave fields on similar spatial scales. The Bragg peaks used to estimate surface velocities are flanked by a weaker "second-order" continuum because of double scattering from two freely propagating waves, as well as scattering from nonlinearly bound waves. This continuum contains contributions from all ocean wave components longer than the Bragg waves, and thus the second-order part of the power spectrum can be inverted to estimate the frequency-direction spectrum of the longer waves (Hasselmann 1971; Weber and Barrick 1977; Wyatt, Ledgard, and Anderson 1997) and near-surface winds via a wind-wave model (Heron and Rose 1986, Paduan et al. 1999; Shen et al. 2012; Kirincich 2016). Although operational wave products are available from PA systems, spatially dependent estimates of winds and waves from DF systems are still under development.

One aspect of HF radar data that deserves special mention is the treatment of the radial velocity data to form gridded products of vector velocities. Although along-radial resolution is constant with range, the azimuthal resolution degrades with range. As a result, most data products of vector velocities use spatial averaging scales three to four times the radial resolution to produce gridded products. Thus, spatial scales shorter than $20-30 \mathrm{~km}$ are generally attenuated in data products made from $5 \mathrm{MHz}$ radars. Additionally, most commercially available systems utilize a temporal sampling window two to three times larger than the reporting interval. Although this acts to reduce the potential gaps in the data set, the amplitudes of higher frequency processes such as the tides can be significantly attenuated. This can be a potentially critical factor in the use of the data sets for model assimilation.

iv. Biological and chemical sensors. Traditionally, in situ measurements of oceanic nutrients, productivity, and water chemistry have been limited to shipboard sampling via bottles and onboard processing using intensive laboratory efforts. However, in situ, autonomous observations of these parameters in the ocean are becoming more prevalent as new, stable technologies are being transitioned into commercially available sensors. A number of sensors for biologically important variables have been available for a few decades. Autonomous sampling estimates of chlorophyll using optical fluorescence, light attenuation, photosynthetically available radiation, dissolved oxygen, and so forth, have been utilized to gauge primary productivity and biomass estimates (Dickey 1991; Grantham et al. 2004). However, these systems are not always straightforward to use, and sensor calibration is more often based on empirical relations between sensor outputs and local system properties than some universal norm. These relations are sometimes stable neither in space nor time. Further, biofouling generally prevents long-term observations with these types of sensors, although some progress has been made (e.g., Gruber et al. 2010). The upshot is that frequent checks against direct measurements are necessary to assure data quality.

The use of autonomous sensors capable of measuring even more complex biological and biochemical parameters in the coastal ocean has exploded in recent years, both in process studies and long-term monitoring. Ultraviolet spectrophotometry of nitrate (e.g., Johnson and Coletti 2002; Sakamoto, Johnson, and Coletti 2009); in situ wet chemistry (e.g., Hanson 
2000); flow cytobots that individually recognize, count, and categorize phytoplankton species (e.g., Campbell et al. 2013); and molecular sensors for potential toxins (e.g., Anderson et al. 2014) are examples of the types of instruments that have been developed and commercialized within the last decade. Of those new classes of sensors, most are focused on coastal areas because of higher power requirements, more onerous operation, maintenance, and calibration, as well as the higher signal-to-noise ratios present. Their use in the coastal ocean has increased dramatically in recent years from small process studies (e.g., Johnson and Coletti 2002; Sigleo et al. 2005; Campbell et al. 2013) to larger-scale use (e.g., Chavez et al. 1997; Johnson et al. 2009; Dulaiova et al. 2010) because of both reduced sensor costs and a realization by nonscientific local ocean stakeholders that ocean biological and chemical information can be critical in decision making (Jannasch et al. 2008; Ruhl et al. 2011).

Thus, many of these biological sensors are now transitioning to operational status and being deployed in service of monitoring harmful algal blooms, counting individual singlecelled organisms via automated microscopes, or detecting changes in key nutrient or chemical parameters of the coastal ocean (e.g., Anderson et al. 2014). In addition to now-standard oxygen and chlorophyll observations, nutrients such as ammonium $\left(\mathrm{NH}_{4}\right)$, nitrate $\left(\mathrm{NO}_{3}\right)$, and phosphate $\left(\mathrm{PO}_{4}\right)$ are being measured in real time via observing system assets (Northeastern Regional Association of Coastal Ocean Observing Systems 2015). Developing sensors are also allowing real-time in situ observations of $\mathrm{pH}, \mathrm{CO}_{2}$, and other carbonate parameters (Fig. 4), yielding observations that are critical for monitoring commercially valuable marine organisms (Barton 2015; Northwest Association of Networked Ocean Observing Systems 2015) but can also be used in constraining coupled models (Banas et al. 2009).

\section{c. Historical measurements}

Sections $4 \mathrm{a}$ and $4 \mathrm{~b}$ have focused on the potential for real-time, or operational, observations of the coastal ocean. In terms of developing and testing ocean prediction systems, there is no reason not to make use of past measurements that were originally made for some other purpose. For example, historical information can provide a useful climatology that sets the background for a predictive capability, defining the range over which realistic results are expected to vary. Almost by definition, ocean climatological data have to come from the historical record. Further, there are coastal examples of focused process studies, such as the 1982-1983 CODE (Coastal Ocean Dynamics Experiment) experiment (e.g., Winant, Beardsley, and Davis 1987) that provide extraordinarily intensive current, wind, and temperature measurements over several months at a time.

There are issues, however, with using historical data. First, one needs to be assured of data quality. Instruments and protocols vary with time and between organizations, and there are indeed well-known examples of systematically poor data quality from particular sources. Second, what is available depends entirely on the objectives of the historical measurement programs. Thus, the data may simply not include the sorts of measurements desired (e.g., the data might only include hydrographic measurements but no direct information on currents), or there may be no information from the particular 

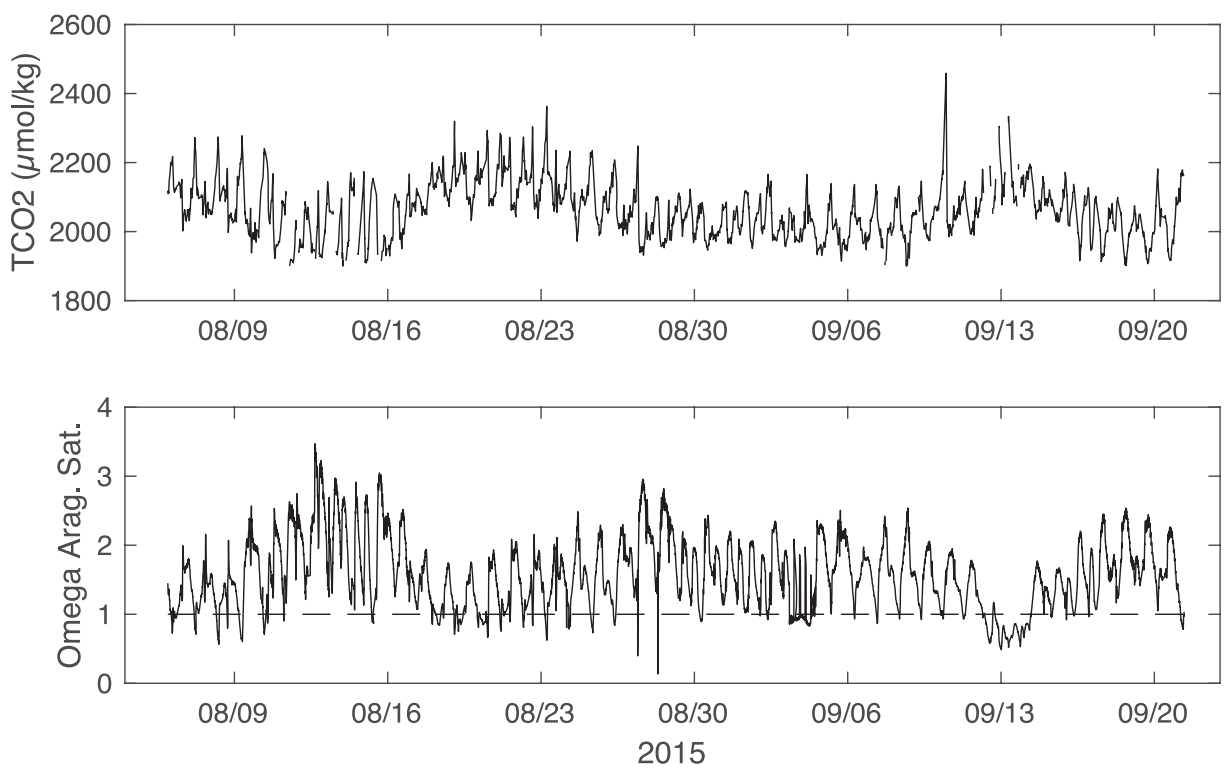

Figure 4. Total $\mathrm{CO}_{2}\left(\mathrm{TCO}_{2}\right.$; top) and the Omega aragonite saturation (Omega arag. sat., $\Omega$; bottom) measured at Whiskey Creek, Oregon, by Oregon State University as part of the Pacific Northwest Regional Ocean Observing System (NANOOS). Subsurface waters upwelled during summer off Oregon contain high levels of $\mathrm{CO}_{2}$, driving the saturation state of aragonite, the source of shell material for commercially important bivalves such as oysters, below $\Omega=1$, leading to dissolution. $\mathrm{CO}_{2}$ and Omega are monitored in real time on the Oregon coast to inform local stakeholders (data accessed from NANOOS 2015).

geographic region that is of current interest. Third, there are numerous historical databases, both nationally and internationally, where one might retrieve historical measurements (e.g., https://www.nodc.noaa.gov/access/services.html; http://ices.dk/marine-data/datasetcollections/Pages/default.aspx), but these archives are not always perfect. For example, some measurements, especially those from unconventional sampling systems or funding sources, do not make it into the archives. Further, in some cases, the desired information might be distributed over several archives, so that searching is not a one-stop process. Unquestionably, data archives are improving considerably, but it seems likely that at least a few data sets will be lost and that many will be underutilized. Regardless, historical measurements represent a rich source of virtually free data, but one that may or may not reflect the needs of the modeler of the present. Although the potential for useful data is high, one should be realistic about expectations.

\section{d. Ongoing observing systems}

There is a remarkable wealth of ongoing measurement programs in the coastal ocean. However, these programs are also extremely diverse in terms of objectives and intensity. 
This diversity means that ongoing programs may not always match the modeler's needs well.

Consider objectives, for example. One of the oldest, and hence most valuable, measurement programs is CalCOFI (California Cooperative Offshore Fisheries Investigations; e.g., Goerike and Ohman 2015 and accompanying articles), a program that has existed since the 1930s. The project was initially driven by a need to understand fluctuations in the sardine fishery off the U.S. West Coast. Thus, the motivation was primarily biological, and there was an emphasis on observing larval fish populations and the variables (chemical or biological) that might affect fluctuations. These are labor-intensive measurements, and so sampling was restricted to a few surveys per year, at most, and to relatively coarse, $O(50$ $\mathrm{km}$ or more), station separations at locations that extend far offshore of the shelf. These sampling intervals were consistent with oceanographic knowledge at the time the program was established. Further, the scope of the program was, to some extent, determined by the state of California's need to pay only to address perceived needs, rather than supporting an ideal, comprehensive ocean observation effort. The CalCOFI program has continued to the present, and in recent years, it has added increasingly sophisticated ocean measurements that greatly enhance the value to a physical oceanographer (e.g., Johnston and Rudnick 2015). However, the longest physical records are those of coarsely sampled temperature and salinity cast observations. These measurements have proved to be extremely valuable in terms of establishing a hydrographic climatology and for understanding interannual variations (e.g., Chelton, Bernal, and McGowan 1982). The CalCOFI program, as valuable as it is, is probably not the system that today's predictive modeler would have defined. Rather, the motivating needs, fiscal reality and the then-existing understanding, shaped the actual program.

Second, the Rutgers system for ocean prediction offshore of New Jersey (e.g., Wilkin and Hunter 2013) represents a more modern example of an integrated observing and modeling system. The model itself, of course, relies on routine wind products for surface forcings and couples to an operational basin-scale ocean model to provide the offshore open boundary conditions. Although the model builds on historical observations and understandings, the core real-time ocean measurements stem from the Mid-Atlantic Regional Association Coastal Ocean Observing System. Specifically, the modeling system depends on HF radar measurements of surface currents and glider measurements of subsurface temperature and salinity along a few discrete transect lines. These observations are routinely qualitycontrolled and then assimilated into a model to create broadly disseminated predictions on a routine basis (http://assets.maracoos.org/). This system, focused primarily on predicting physical conditions, has been operational since around 2010 and demonstrates physical predictability based on a relatively limited set of input measurements. This system is an example of a successful ongoing observation/prediction system that uses a fairly limited input data set.

In contrast to the Rutgers system, the developing Coastal Observing System for Northern and Arctic Seas (COSYNA) (Baschek et al. 2017) takes a broader approach to processes in 
the German Bight of the North Sea. This system carries out a broad suite of observations, including fixed-site time series (permanent anchored poles and bottom platforms), mobile measurements (gliders, ship-based surveys, and ship of opportunity observations), remote sensing, surface wave observations, and HF radar estimates of currents. In addition to purely physical variables, this system measures such nonphysical quantities as turbidity, suspended matter concentration, and chlorophyll and oxygen concentrations. All of these measurements are made on an ongoing basis, and the quality-controlled information is made available in near real time to both scientific and practical (e.g., wind energy or environmental management) users. COSYNA is now in the process of developing a predictive modeling system that takes advantage of these various data streams. Undoubtedly, making this system operational will lead to iterations between observational and modeling requirements.

These three systems represent a modest sampling of extant coastal observing systems, ranging from established to developing and varying in terms of both the audiences to be served and in the extent to which the models and observations are integrated. One common thread, however, is that these valuable long-term observing programs only obtain continued funding because they address a practical need, such as fisheries, weather forecasting, or pollution monitoring. The diversity of motivations for sponsorship means that ongoing programs reflect funding from a range of sources (including local governments, private enterprise, and national governments) that reflect a range of desired outcomes. The scale of the measurements may be modest, such as simply tracking power plant intake water temperatures, or very ambitious, such as CalCOFI or COSYNA. In many cases, existing local needs-based measurements may not be widely known, nor might the data be readily accessible. Examples of this diversity can be found, for example, in Vincent, Royer, and Brink (1993). Thus, simply discovering and gaining access to data sets can be an issue.

There is a growing cohesiveness among the diverse coastal ocean observing systems. The global nexus of this coordination is the International Oceanographic Commission, and this organization in turn deals with a number of regional consortia of observing systems. The website (http://imos.org.au/gra.html) provides links to the regional consortia, which in turn can lead to the individual coastal observing systems. In the United States, for example, the consortium is the Integrated Ocean Observing System (IOOS; e.g., Malone and Cole 2000), a network of needs-based ocean observing systems that are organized regionally. Thus, a moored current meter deployment might be motivated or sustained because of the needs of the local fishing community. Some aspects of IOOS, such as surface current measurements via HF radar, reflect measurements that are genuinely of a regional scope. Although IOOS measurements are sometimes used to help drive ocean prediction systems (e.g., Wilkin and Hunter 2013), the motivation is often not tied to models. Although the data sets may not be what an oceanographer might design for research purposes, they have the tremendous advantage that they are driven by practical needs, so that the funding, and hence measurements, might be expected to be sustained over very long time scales.

Another trend is the increasing prominence of sustained, science-driven ocean observatories such as represented by the U.S. Ocean Observing Initiative (e.g., Cowles et al. 2010) and 
Neptune Canada (Heeseman et al. 2014). Typically, the observatory involves very sophisticated measurement systems deployed for an indefinite period at a relatively small number of discrete locations. For example, in the Middle Atlantic Bight, the observatory will include only a few nodal locations on the shelf, although these fixed point measurements will be supplemented by some AUV (glider) sampling (Cowles et al. 2010). In common with IOOS, observatory observations will be made publicly available within near real time. In contrast to IOOS, where measurements may be relatively unsophisticated but collectively cover a broad spatial domain for extended periods, observatory measurements focus on making diverse, comprehensive observations at a limited number of sites. Presumably, at least some observatory resources will be moved geographically as scientific questions are resolved and new ones arise elsewhere. Thus, the data streams from needs-driven observing systems and from science-driven observatories should be seen as complementary.

Certainly, over the last decades, there has been a trend toward developing sustained observing programs in the coastal ocean. From a practical standpoint, these systems are on hand to deal with needs, such as search and rescue, as they arise. From a scientific standpoint, these sustained measurements allow insights about multiyear variability that is inaccessible with traditional expeditionary approaches. However, sustained measurements place a real strain on limited funding resources. Thus, they need to be increasingly well justified for practical or scientific reasons. On the other hand, technologies are improving, and newer systems such as shore-based coastal radars can provide impressive data sets for modest per-observation costs. Two trends seem clear-cut. One is that there will be an increasing recognition of the practical needs for better coastal ocean observations and predictions. The drivers might include navigational hazards, pollution issues, or search and rescue. Second, the need to leverage constrained resources and the growing recognition of the global scale of many problems will lead to a greater degree of international collaboration. This collaboration will likely be most evident for basin-scale oceanographic issues, but it will likely have coastal aspects as well.

\section{Conclusions}

Although the coastal ocean places special, stricter demands on observational and modeling systems, it has a high priority for many practical reasons, and its proximity to land allows for relatively good data intensity. Whether this higher intensity is sufficient to compensate for naturally shorter (than in the open ocean) space and time scales depends on the problem at hand. Specifically, some variables, such as along-shelf currents, have relatively large scales and mainly need only regional winds to gain some predictability. On the other hand, some variables, such as cross-shelf currents below the mixed layer, have very short length scales and might ultimately only be predictable on a stochastic basis (e.g., in terms of their statistics rather than exact instantaneous fields).

Undoubtedly, coastal ocean prediction systems will only improve over the coming years, if for no other reason than that computing capabilities will certainly improve. Obtaining the 
required observational base, however, will be challenging for a number of reasons. Some interesting issues include the following:

-In some cases, prediction at a set location requires information from adjacent locations. In the case of a large country, or one with cooperative neighbors, this presents no major problem. However, one can readily imagine situations where friction among neighboring nations makes cooperation in coastal ocean prediction difficult.

-As more demands are placed on the coastal ocean, conflicts arise over space allocation. Trade-offs need to be made, for example, with regard to competing claims for conservation, fishing, and wind power in a given setting. To the extent that fixed observing assets, such as moorings or observatory nodes, claim a semipermanent ocean presence, a good deal of care needs to be taken to assure that all interested parties are agreed on spatial allocations.

- In many cases, such as that of a catastrophic oil spill, the need for a predictive capability at one particular place requires the prompt deployment of observational assets at appropriate locations. There is thus a need to develop and make available readily deployed instrumentation that can provide real-time data. Further, knowledge of the underlying coastal ocean processes must be at a state where we can know, on only a few hours' notice, where best to deploy these assets.

Thus, we expect that, although coastal ocean observation and prediction capabilities will improve dramatically over the coming decades, challenges will remain to stimulate the coming generations.

Acknowledgments. KB gratefully acknowledges support from the U.S. National Science Foundation, Physical Oceanography (grant OCE-1433953) and Ocean Biology (grant OCE-1258667) programs. AK gratefully acknowledges support from the U.S. National Science Foundation, Physical Oceanography (grant OCE-1332646).

\section{REFERENCES}

Alsdorf, D., L.-L. Fu, N. Mognard, A. Cazenave, E. Rodriguez, D. Chelton, and D. Lettenmaier. 2007. Measuring global oceans and terrestrial freshwater from space. Eos, Trans., Am. Geophys. Union, 88, 253-257. doi: 10.1029/2007EO240002

Anderson, D. M., B. A. Keafer, J. L. Kleindinst, D. J. McGillicuddy, Jr., J. L. Martin, K. Norton, C. H. Pilskaln, J. L. Smith, C. R. Sherwood, and B. Butman. 2014. Alexandrium fundyense cysts in the Gulf of Maine: Long-term time series of abundance and distribution, and linkages to past and future blooms. Deep Sea Res., Part II, 103, 6-26. doi: 0.1016/j.dsr2.2013.10.002

Arnold, C. P., Jr., and C. H. Dey. 1986. Observing-systems simulation experiments: Past, present, and future. Bull. Am. Meteorol. Soc., 67(6), 687-695. doi: 10.1175/1520-0477(1986)067\%3C0687: OSSEPP\%3E2.0.CO;2

Austin, J. A., and J. A. Barth. 2002. Variation in the position of the upwelling front on the Oregon shelf. J. Geophys. Res.: Oceans, 107(C11), 3180. doi: 10.1029/2001JC000858

Aydoğdu, A., N. Pinardi, J. Pistoia, M. Martinelli, A. Belardinelli, and S. Sparnocchia. 2016. Assimilation experiments for the Fishery Observing System in the Adriatic Sea. J. Mar. Syst., 162, 126-136. doi: 10.1016/j.jmarsys.2016.03.002 
Banas, N. S., E. J. Lessard, R. M. Kudela, P. MacCready, T. D. Peterson, B. M. Hickey, and E. Frame. 2009. Planktonic growth and grazing in the Columbia River plume region: A biophysical model study. J. Geophys. Res.: Oceans, 114, C00B06. doi: 10.1029/2008JC004993

Barton, A., G. G. Waldbusser, R. A. Feely, S. B. Weisberg, J. A. Newton, B. Hales, S. Cudd, et al. 2015. Impacts of coastal acidification on the Pacific Northwest shellfish industry and adaptation strategies implemented in response. Oceanography, 28(2), 146-159. doi: 10.5670/oceanog.2015.38

Baschek, B., F. Schroeder, H. Brix, R. Riethmüller, T. H. Badewien, G. Breitbach, B. Brügge, et al. 2016. The Coastal Observing System for Northern and Arctic Seas (COSYNA). Ocean Sci. 13, 379-410. doi: 10.5194/os-13-379-2017

Beman, J. M., K. R. Arrigo, and P. A. Matson. 2005. Agricultural runoff fuels large phytoplankton blooms in vulnerable areas of the ocean. Nature, 434(7030), 211-214. doi: 10.1038/nature03370

Bernard, E. N., and A. R. Robinson, eds. 2009. The Sea, Vol. 15, Tsunamis. Cambridge, MA: Harvard University Press.

Brink, K. H. 1987. Coastal ocean physical processes. Rev. Geophys., 25(2), 204-216. doi: 10.1029/ RG025i002p00204

Brink, K. H. 1995. Tidal and lower frequency currents above Fieberling Guyot. J. Geophys. Res.: Oceans, 100, 10817-10832. doi: 10.1029/95JC00998

Brink, K. H. 1998. Wind-driven currents over the continental shelf, in The Sea, Vol. 10, The Global Coastal Ocean: Processes and Methods, K. H. Brink and A. R. Robinson, eds. New York: John Wiley and Sons, 3-20.

Brink, K. H., F. Bahr, and R. K. Shearman. 2007. Alongshore currents and mesoscale variability near the shelf edge off northwestern Australia. J. Geophys. Res.: Oceans, 112, C05013. doi: 10.1029/2006JC003725

Brink, K. H. and H. Seo, 2016. Continental shelf baroclinic instability. Part II: Oscillating wind forcing. J. Phys. Oceanogr., 46, 569-582. doi: 10.1175/JPO-D-15-0048.1

Brown, W. S., J. D. Irish, and C. D. Winant. 1987. A description of subtidal pressure field observations on the northern California continental shelf during the Coastal Ocean Dynamics Experiment. J. Geophys. Res.: Oceans, 92, 1605-1635. doi: 10.1029/JC092iC02p01605

Campbell, L., D. W. Henrichs, R. J. Olson, and H. M. Sosik. 2013. Continuous automated imagingin-flow cytometry for detection and early warning of Karenia brevis blooms in the Gulf of Mexico. Environ. Sci. Pollut. Res., 20, 6896-6902. doi: 10.1007/s11356-012-1437-4

Castelao, R. M., and R. He. 2013. Mesoscale eddies in the South Atlantic Bight. J. Geophys. Res.: Oceans, 118(10), 5720-5731. doi: 10.1002/jgrc.20415

Chaigneau, A., G. Eldin, and B. Dewitte. 2009. Eddy activity in the four major upwelling systems from satellite altimetry (1992-2007). Prog. Oceanogr., 83(1-4), 117-123. doi: 10.1016/j.pocean. 2009.07.012

Chavez, F. P., J. T. Pennington, R. Herlien, H. Jannasch, G. Thurmond, and G. E. Friederich. 1997. Moorings and drifters for real-time interdisciplinary oceanography. J. Atmos. Oceanic Technol., 14(5), 1199-1211. doi: 10.1175/1520-0426(1997)014\%3C1199:MADFRT\%3E2.0.CO;2

Chelton, D. B., P. A. Bernal, and J. A. McGowan. 1982. Large-scale interannual physical and biological interactions in the California Current. J. Mar. Res., 40, 1095-1125.

Chelton, D. B., J. C. Ries, B. J. Haines, L.-L. Fu, and P. S. Callahan. 2001. Satellite altimetry, in Satellite Altimetry and Earth Sciences: A Handbook of Techniques and Applications, L.-L. Fu and A. Cazenave, eds. San Diego, CA: Academic Press, 1-168.

Chelton, D. B., M. G. Schlax, and R. M. Samelson. 2007. Summertime coupling between sea surface temperature and wind stress in the California Current System. J. Phys. Oceanogr., 37, 495-517. doi: $10.1175 / \mathrm{JPO} 3025.1$ 
Clarke, A. J., and S. Van Gorder. 1994. On ENSO coastal currents and sea levels. J. Phys. Oceanogr., 24, 661-680. doi: 10.1175/1520-0485(1994)024\%3C0661:OECCAS\%3E2.0.CO;2

Connolly, T. P., and S. J. Lentz. 2014. Interannual variability of wintertime temperature on the inner continental shelf of the Middle Atlantic Bight. J. Geophys. Res.: Oceans, 119, 6269-6285. doi: 10.1002/2014JC010153

Cowles, T., J. Delaney, J. Orcutt, and R. Weller. 2010. The Ocean Observatories Initiative: Sustained ocean observing across a range of spatial scales. Mar. Technol. Soc. J., 44(6), 54-64. doi: 10.4031/MTSJ.44.6.21

Dall'Olmo, G., A. A. Gitelson, D. C. Rundquist, B. Leavitt, T. Barrow, and J. C. Holz. 2005. Assessing the potential of SeaWiFS and MODIS for estimating chlorophyll concentration in turbid productive waters using red and near-infrared bands. Remote Sens. Environ., 96(2), 176-187. doi: 10.1016/j.rse.2005.02.007

Dever, E. P. 1997. Subtidal velocity correlation scales on the northern California shelf. J. Geophys. Res.: Oceans, 102(C4), 8555-8572. doi: 10.1029/96JC03451

Dever, E. P. 2004. Objective maps of near-surface flow states near Point Conception, California. J. Phys. Oceanogr., 34(2), 444-461. doi: 10.1175/1520-0485(2004)034\%3C0444:OMONFS\% 3E2.0.CO;2

Dickey, T. D. 1991. The emergence of concurrent high-resolution physical and bio-optical measurements in the upper ocean and their applications. Rev. Geophys., 29(3), 383-413. doi: 10.1029/ 91RG00578

Dobbins, E. L., A. J. Hermann, P. Stabeno, N. A. Bond, and R. C. Steed. 2009. Modeled transport of freshwater from a line-source in the coastal Gulf of Alaska. Deep Sea Res., Part II, 56, 2409-2426. doi: 10.1016/j.dsr2.2009.02.004

Dulaiova, H., R. Camilli, P. B. Henderson, and M. A. Charette. 2010. Coupled radon, methane and nitrate sensors for large-scale assessment of groundwater discharge and non-point source pollution to coastal waters. J. Environ. Radioact., 101(7), 553-563. doi: 10.1016/j.jenvrad.2009.12.004

Emery, B. M., L. Washburn, and J. A. Harlan, 2004. Evaluating radial current measurements from CODAR high-frequency radars with moored current meters. J. Atmos. Oceanic Technol., 21(8), 1259-1271.

Geyer, W. R., and P. MacCready. 2014. The estuarine circulation. Annu. Rev. Fluid Mech., 46, 175197. doi: 10.1146/annurev-fluid-010313-141302

Giese, G. S., D. C. Chapman, M. G. Collins, R. Encarnacion, and G. Jacinto. 1998. The coupling between harbor seiches at Palawan Island and Sulu Sea internal solitons. J. Phys. Oceanogr., 28, 2418-2426. doi: 10.1175/1520-0485(1998)028\%3C2418:TCBHSA\%3E2.0.CO;2

Gitelson, A. A., G. Dall'Olmo, W. Moses, D. C. Rundquist, T. Barrow, T. R. Fisher, D. Gurlin, and J. Holz. 2008. A simple semi-analytical model for remote estimation of chlorophyll- $a$ in turbid waters: Validation. Remote Sens. Environ., 112(9), 3582-3593. doi: 10.1016/j.rse.2008.04.015

Glenn, S., and O. Schofield, 2009. Growing a distributed ocean observatory: Our view from the COOL room. Oceanography, 22(2), 128-145.

Glenn, S. M., and C. C. Ebbesmeyer 1994. The structure and propagation of a Gulf Stream frontal eddy along the North Carolina shelf break. J. Geophys. Res.: Oceans, 99, 5029-5046. doi: 10.1029/93JC02786

Goebel, N. L., C. A. Edwards, J. P. Zehr, and M. J. Follows. 2010. An emergent community ecosystem model applied to the California Current System. J. Mar. Syst., 83(3-4), 221-241. doi: 10.1016/j.jmarsys.2010.05.002

Goericke, R., and M. D. Ohman. 2015. Introduction to CCE-LTER: Responses of the California Current ecosystem to climate forcing. Deep Sea Res., Part II, 112, 1-5. doi: 10.1016/j.dsr2.2014.12.001 
Grantham, B. A., F. Chan, K. J. Nielsen, D. S. Fox, J. A. Barth, A. Huyer, J. Lubchenco, and B. A. Menge. 2004. Upwelling-driven nearshore hypoxia signals ecosystem and oceanographic changes in the northeast Pacific. Nature, 429(6993), 749-754. doi: 10.1038/nature02605

Gruber, N., S. C. Doney, S. R. Emerson, D. Gilbert, T. Kobayashi, A. Körtzinger, G. C. Johnson, K. S. Johnson, S. C. Riser, and O. Ulloa. 2010. Adding oxygen to Argo: Developing a global insitu observatory for ocean deoxygenation and biogeochemistry, in Proceedings of OceanObs'09: Sustained Ocean Observations and Information for Society (Vol. 2), Venice, Italy, 21-25 September 2009, J. Hall, D. E. Harrison, and D. Stammer, eds. European Space Agency (ESA) Publication WPP-306. Rome: ESA. doi: 10.5270/OceanObs09.cwp.39

Haidvogel, D. B., and T. Keffer. 1984. Tracer dispersal by mid-ocean mesoscale eddies. Part I. Ensemble statistics. Dyn. Atmos. Oceans, 8, 1-40. doi: 10.1016/0377-0265(84)90002-2

Hanson, A. K. 2000. A new in situ chemical analyzer for mapping coastal nutrient distributions in real time, in OCEANS 2000 MTS/IEEE Conference and Exhibition (Vol. 3). Washington, DC: Oceans 2000 MTS/IEEE Conference Committee, 1975-1982.

Harlan, J., E. Terrill, L. Hazard, C. Keen, D. Barrick, C. Whelan, S. Howden, and J. Kohut. 2010. The Integrated Ocean Observing System high-frequency radar network: Status and local, regional, and national applications. Mar. Technol. Soc. J., 44(6), 122-132. doi: 10.4031/MTSJ.44.6.6

Hasselmann, K. 1971. Determination of ocean wave spectra from Doppler radio return from the sea surface. Nature, 229, 16-17. doi: 10.1038/physci229016a0

Heesemann, M., T. L. Insua, M. Scherwath, S. K. Juniper, and K. Moran. 2014. Ocean Networks Canada: From geohazards research laboratories to Smart Ocean Systems. Oceanography, 27(2), 151-153. doi: 10.5670/oceanog.2014.50

Heron, M., and R. Rose 1986. On the application of HF ocean radar to the observation of temporal and spatial changes in wind direction. IEEE J Oceanic Eng, 11(2), 210-218. doi: 10.1109/JOE.1986.1145173

Hill, A. E. 1998. Buoyancy effects in coastal and shelf seas, in The Sea, Vol. 10, The Global Coastal Ocean: Processes and Methods, K. H. Brink and A. R. Robinson, eds. New York: John Wiley and Sons, 21-62.

Hong, B. G., W. Sturgis, and A. J. Clarke. 2000. Sea level on the U.S. east coast: Decadal variability caused by open ocean wind-curl forcing. J. Phys. Oceanogr., 30, 2088-2098. doi: 10.1175/15200485(2000)030\%3C2088:SLOTUS\%3E2.0.CO;2

Hu, C., J. Cannizzaro, K. L. Carder, F. E. Muller-Karger, and R. Hardy. 2010. Remote detection of Trichodesmium blooms in optically complex coastal waters: Examples with MODIS full-spectral data. Remote Sens. Environ., 114(9), 2048-2058. doi: 10.1016/j.rse.2010.04.011

Jannasch, H. W., L. J. Coletti, K. S. Johnson, S. E. Fitzwater, J. A. Needoba, and J. N. Plant. 2008. The Land/Ocean Biogeochemical Observatory: A robust networked mooring system for continuously monitoring complex biogeochemical cycles in estuaries. Limnol. Oceanogr.: Methods, 6(7), 263276. doi: $10.4319 /$ lom.2008.6.263

Johnson, K. S., W. M. Berelson, E. S. Boss, Z. Chase, H. Claustre, S. R. Emerson, N. Gruber, A. Kortzinger, M. J. Perry, and S. C. Riser. 2009. Observing biogeochemical cycles at global scales with profiling floats and gliders: Prospects for a global array. Oceanography, 22(3), 216-225.

Johnson, K. S., and L. J. Coletti. 2002. In situ ultraviolet spectrophotometry for high resolution and long-term monitoring of nitrate, bromide and bisulfide in the ocean. Deep Sea Res., Part I, 49(7), 1291-1305. doi: 10.1016/S0967-0637(02)00020-1

Johnston, T. M. S., and D. L. Rudnick, 2015. Trapped diurnal internal tides, propagating semidiurnal internal tides, and mixing estimates in the California Current System from sustained glider observations, 2006-2012. Deep Sea Res., Part II, 112, 61-78. doi: 10.1016/j.dsr2.2014.03.009 
Kaplan, D. M. and F. Lekien, 2007. Spatial interpolation and filtering of surface current data based on open-boundary modal analysis. Journal of Geophysical Research: Oceans, 112(12), 1-20. doi: 10.1029/2006JC003984

Kaufmann, R. K., L. Zhou, Y. Knyazikhin, V. Shabanov, R. B. Myneni, and C. J. Tucker. 2000. Effect of orbital drift and sensor changes on the time series of AVHRR vegetation index data. IEEE Trans. Geosci. Remote Sens., 38(6), 2584-2597. doi: 10.1109/36.885205

Khlopenkov, K. V., and A. P. Trishchenko. 2008. Implementation and evaluation of concurrent gradient search method for reprojection of MODIS level 1B imagery. IEEE Trans. Geosci. Remote Sens., 46(7), 2016-2027. doi: 10.1109/TGRS.2008.916633

Kim, S. Y., E. J. Terrill, B. D. Cornuelle, B. Jones, L. Washburn, M. A. Moline, J. D. Paduan, et al. 2011. Mapping the U.S. West Coast surface circulation: A multiyear analysis of high-frequency radar observations. J. Geophys. Res.: Ocean, 116, C03011. doi: 10.1029/2010JC006669

Kirincich, A. 2016. Remote sensing of the surface wind field over the coastal ocean via direct calibration of HF radar backscatter power. J. Atmos. Oceanic Technol., 33(7), 1377-1392. doi: 10.1175/ JTECH-D-15-0242.1

Kirincich, A. R., T. de Paolo, and E. Terrill. 2012. Improving HF radar estimates of surface currents using signal quality metrics, with application to the MVCO high-resolution radar system. J. Atmos. Oceanic Technol., 29(9), 1377-1390. doi: 10.1175/JTECH-D-11-00160.1

Kirincich, A. R., S. J. Lentz, J. T. Farrar, and N. K. Ganju. 2013. The spatial structure of tidal and mean circulation over the inner shelf south of Martha's Vineyard, Massachusetts. J. Phys. Oceanogr., 43(9), 1940-1958. doi: 10.1175/JPO-D-13-020.1

Kohut, J. T., H. J. Roarty, and S. M. Glenn, 2006. Characterizing observed environmental variability with HF doppler radar surface current mappers and acoustic doppler current profilers: Environmental variability in the coastal ocean. IEEE Journal of Oceanic Engineering, 31(4), 876-884. doi: 10.1109/JOE.2006.886095

Kundu, P. K., and J. S. Allen. 1976. Some three-dimensional characteristics of low-frequency current fluctuations near the Oregon coast. J. Phys. Oceanogr., 6, 181-199. doi: 10.1175/1520-0485(1976) 006\%3C0181:STDCOL\%3E2.0.CO;2

Kurapov, A. L., G. D. Egbert, J. S. Allen, and R. N. Miller. 2009. Representer-based analyses in the coastal upwelling system. Dyn. Atmos. Oceans, 48(1-3), 198-218. doi: 10.1016/j.dynatmoce. 2008.09.002

Kurapov, A. L., G. D. Egbert, J. S. Allen, R. N. Miller, S. Y. Erofeeva, and P. M. Kosro. 2003. The $M_{2}$ internal tide off Oregon: Inferences from data assimilation. J. Phys. Oceanogr., 33, 1733-1757. doi: $10.1175 / 2397.1$

Laws, K. 2001. Measurements of Near Surface Ocean Currents Using HF Radar. PhD diss. Santa Cruz: University of California, Santa Cruz.

Lentz, S. J., and M. R. Fewings. 2012. The wind- and wave-driven inner-shelf circulation. Annu. Rev. Mar. Sci., 4, 317-343. doi: 10.1146/annurev-marine-120709-142745

Lentz, S., R. T. Guza, S. Elgar, F. Fedderson, and T. H. C. Herbers. 1999. Momentum balances on the North Carolina inner shelf. J. Geophys. Res.: Oceans, 104, 18205-18226. doi: 10.1029/ 1999JC900101

Linder, C. A., and G. Gawarkiewicz. 1998. A climatology of the shelfbreak front in the Middle Atlantic Bight. J. Geophys. Res.: Oceans, 103, 18405-18423. doi: 10.1029/98JC01438

Liu, Y., H. Kerkering, and R. H. Weisberg, eds. 2015. Coastal Ocean Observing Systems. London: Academic Press.

Malone, T. C., and M. Cole. 2000. Toward a global scale coastal ocean observing system. Oceanography, 13, 7-11. doi: 10.5670/oceanog.2000.48 
Moore, T. S., K. M. Mullagh, R. R. Holyoke, A. S. Madison, M. Yücel, and G. W. Luther III. 2009. Marine chemical technology and sensors for marine waters: Potentials and limits. Annu. Rev. Mar. Sci., 1, 91-115. doi: 10.1146/annurev.marine.010908.163817

Moses, W. J., A. A. Gitelson, R. L. Perk, D. Gurlin, D. C. Rundquist, B. C. Leavitt, T. M. Barrow, and P. Brakhage. 2012. Estimation of chlorophyll- $a$ concentration in turbid productive waters using airborne hyperspectral data. Water Res., 46(4), 993-1004. doi: 10.1016/j.watres.2011.11.068

Murty, T. S. 1984. Storm Surges: Meteorological Ocean Tides. Canadian Bulletin of Fisheries and Aquatic Sciences, 212. Ottawa, ON: Department of Fisheries and Oceans.

Northeastern Regional Association of Coastal Ocean Observing Systems (NERACOOS). 2015. Integrated Nutrient Observatory. Portsmouth, NH: NERACOOS. http://neracoos.org/ nutrientobservatory

Northwest Association of Networked Ocean Observing Systems (NANOOS). 2015. WCSH_Whiskey1: Whiskey Creek CO2 and Aragonite Saturation Observations. NANOOS Visualization System (NVS): Shellfish Growers. Seattle, WA: NANOOS. http://nvs.nanoos.org/ ShellfishGrowers

Ohlmann, C., P. White, L. Washburn, B. Emery, E. Terrill, and M. Otero. 2007. Interpretation of coastal HF radar-derived surface currents with high-resolution drifter data. J. Atmos. Oceanic Technol., 24, 666-680. doi: 10.1175/JTECH1998.1

Oke, P. R., J. S. Allen, R. N. Miller, G. D. Egbert, and P. M. Kosro. 2002. Assimilation of surface velocity data into a primitive equation coastal ocean model. J. Geophys. Res.: Oceans, 107(C9), 3122. doi: 10.1029/2000JC000511

Oke, P. R., P. Sakov, and E. Schulz. 2009. A comparison of shelf observation platforms for assimilation in an eddy-resolving ocean model. Dyn. Atmos. Oceans, 48(1-3), 121-142. doi: 10.1016/ j.dynatmoce.2009.04.002

Olascoaga, M. J., I. I. Rypina, M. G. Brown, F. J. Beron-Vera, H. Koçak, L. E. Brand, G. R. Halliwell, and L. K. Shay. 2006. Persistent transport barrier on the West Florida Shelf. Geophys. Res. Lett., 33(22), L22603. doi: 10.1029/2006GL027800

Paduan, J. D., R. Delgado, J. F. Vesecky, Y. Fernandez, J. Daida, and C. Teague. 1999. Mapping Coastal Winds with HF Radar, in Proceedings of the IEEE Sixth Working Conference on Current Measurement, S. P. Anderson, E. A. Terray, J. A. Rizoli White, and A. J. Williams III, eds. Piscataway, NJ: IEEE, 28-32.

Paduan, J. D., and H. C. Graber. 1997. Introduction to high-frequency radar: Reality and myth. Oceanography, 10(2), 36-39. doi: 10.5670/oceanog.1997.18

Paduan, J. D., K. C. Kim, M. S. Cook, and F. P. Chavez, 2006. Calibration and validation of directionfinding current observations. IEEE J. Oceanic Eng., 31(4), 862-875.

Paduan, J. D., and L. Washburn. 2013. High-frequency radar observations of ocean surface currents. Annu. Rev. Mar. Sci., 5, 115-136. doi: 10.1146/annurev-marine-121211-172315

Parker, B. B., ed. 1991. Tidal Hydrodynamics. New York: John Wiley and Sons.

Pascual, A., A. Lana, C. Troupin, S. Ruiz, Y. Faugère, R. Escudier, and J. Tintoré. 2015. Assessing SARAL/AltiKa data in the coastal zone: Comparisons with HF radar observations. Mar. Geod., 38, 260-276. doi: 10.1080/01490419.2015.1019656

Rabalais, N. N. 2005. Eutrophication, in The Sea, Vol. 13, The Global Coastal Ocean: Multiscale Interdisciplinary Processes. A. R. Robinson and K. H. Brink, eds. Cambridge, MA: Harvard University Press, 821-866.

Robinson, A., P. Lermusiaux, and N. Sloan. 1998. Data assimilation, in The Sea, Vol. 10, The Global Coastal Ocean: Processes and Methods, K. H. Brink and A. R. Robinson, eds. New York: John Wiley and Sons, 541- 594. 
Ruhl, H. A., L. Géli, Y. Auffret, and J. Grienert. 2011. Science Modules of the European Seas Observatory NETwork (ESONET): Project Contract No. 036851. Brussels: European Commission. Sakamoto, C. M., K. S. Johnson, and L. J. Coletti. 2009. Improved algorithm for the computation of nitrate concentrations in seawater using an in situ ultraviolet spectrophotometer. Limnol. Oceanogr.: Methods, 7(1), 132-143. doi: 10.4319/lom.2009.7.132

Sallenger A. H., Jr., J. H. List, G. Gelfenbaum, R. P. Stumpf, and M. Hansen. 1995. Large wave at Daytona Beach, Florida, explained as a squall-line surge. J. Coastal Res., 11, 1383-1388.

Schaeffer, A., M. Roughan, E. M. Jones, and D. White. 2016. Physical and biogeochemical spatial scales of variability in the East Australian Current separation from shelf glider measurements. Biogeosciences, 13, 1967-1975. doi: 10.5194/bg-13-1967-2016

Schmitz, W. J., Jr., 1988. Exploration of the eddy field in the midlatitude North Pacific. J. Phys. Oceanogr., 18, 459-468. doi: 10.1175/1520-0485(1988)018\%3C0459:EOTEFI\%3E2.0.CO;2

Shadden, S. C., F. Lekien, J. D. Paduan, F. P. Chavez, and J. E. Marsden 2009. The correlation between surface drifters and coherent structures based on high-frequency radar data in Monterey Bay. Deep Sea Res., Part II, 56(3-5), 161-172. doi: org/10.1016/j.dsr2.2008.08.008

Shen, W., K.-W. Gurgel, G. Voulgaris, T. Schlick, and D. Stammer. 2012. Wind-speed inversion from HF radar first-order backscatter signal. Ocean Dyn., 62(1), 105-121. doi: 10.1007/s10236-011$0465-9$

Sigleo, A. C., C. W. Mordy, P. Stabeno, and W. E. Frick. 2005. Nitrate variability along the Oregon coast: Estuarine-coastal exchange. Estuarine, Coastal Shelf Sci., 64(2-2), 211-222. doi: 10.1016/ j.ecss.2005.02.018

Simpson, J. H. 1998. Tidal processes in shelf seas, in The Sea, Vol. 10, The Global Coastal Ocean: Processes and Methods, K. H. Brink and A. R. Robinson, eds. New York: John Wiley and Sons, 113-150.

Smith, R. L. 1974. A description of current, wind, and sea level variations during coastal upwelling off the Oregon coast, July-August 1972. J. Geophys. Res., 79, 435-443. doi: 10.1029/ JC079i003p00435

Spillane, M. C., D. B. Enfield, and J. S. Allen. 1987. Intraseasonal oscillation in sea level along the west coast of the Americas. J. Phys. Oceanogr., 17, 313-325. doi: 10.1175/1520-0485(1987)017\% 3C0313:IOISLA\%3E2.0.CO;2

Stammer, D., A. Cazenave, R. M. Ponte, and M. E. Tamisiea. 2013. Causes for contemporary regional sea level changes. Annu. Rev. Mar. Sci., 5, 21-46. doi: 10.1146/annurev-marine-121211-172406

Stewart, R. H. and J. W. Joy, 1974. HF radio measurements of surface currents. Deep-sea Res., 21, 1039-1049.

Strub, P. T., and C. James. 2000. Altimeter-derived variability of surface velocities in the California Current System: 2. Seasonal circulation and eddy statistics. Deep Sea Res., Part II, 47(5-6), 831870. doi: 10.1016/S0967-0645(99)00129-0

Strub, P. T., C. James, V. Combes, R. P. Matano, A. R. Piola, E. D. Palma, M. Saraceno, R. A. Guerrero, H. Fenco, and L. A. Ruiz-Etcheverry. 2015. Altimeter-derived seasonal circulation on the southwest Atlantic shelf: $27^{\circ}-43^{\circ}$ S. J. Geophys. Res.: Oceans, 120, 3391-3418. doi: 10.1002/2015JC010769

Ullman, D. S. and D. L. Codiga, 2004. Seasonal variation of a coastal jet in the Long Island Sound outflow region based on HF radar and Doppler current observations. Journal of Geophysical Research, 109(C7), C07S06. doi: 10.1029/2002JC001660

Ullman, D. S., J. O'Donnell, J. Kohut, T. Fake, and A. Allen. 2006. Trajectory prediction using HF radar surface currents: Monte Carlo simulations of prediction uncertainties. J. Geophys. Res.: Oceans, 111, C12005. doi: 10.1029/2006JC003715 
Vignudelli, S., P. Cipollini, L. Roblou, F. Lyard, G. P. Gasparini, G. Manzella, and M. Astraldi. 2005. Improved satellite altimetry in coastal systems: Case study of the Corsica Channel (Mediterranean Sea). Geophys. Res. Lett., 32, L07608. doi: 10.1029/2005GL022602

Vignudelli, S., A. G. Kostianoy, P. Cipollini, and J. Benveniste, eds. 2011. Coastal Altimetry. Berlin: Springer.

Vincent, C. L., T. C. Royer, and K. H. Brink. 1993. Coastal Ocean Processes: Long Time Series Measurements in the Coastal Ocean: A Workshop. Woods Hole Oceanographic Institution Technical Report, WHOI-93-49. Woods Hole, MA: Woods Hole Oceanographic Institution.

Weber, B. L., and D. E. Barrick. 1977. On the nonlinear theory for gravity waves on the ocean's surface. Part I: Derivations. J. Phys. Oceanogr., 7(1), 3-10. doi: 10.1175/1520-0485(1977)007\% 3C0003:OTNTFG\%3E2.0.CO;2

Wilkin, J. L., and E. J. Hunter. 2013. An assessment of the skill of real-time models of MidAtlantic Bight continental shelf circulation. J. Geophys. Res.: Oceans, 118(6), 2919-2933. doi: $10.1002 /$ jgrc. 20223

Winant, C. D., R. C. Beardsley, and R. E. Davis. 1987. Moored wind, temperature, and current observations made during Coastal Ocean Dynamics Experiments 1 and 2 over the northern California continental shelf and upper slope. J. Geophys. Res.: Oceans, 92, 1569-1604. doi: 10.1029/JC092iC02p01569

Winant, C. D., C. E. Dorman, C. A. Friehe, and R. C. Beardsley. 1988. The marine layer off northern California: An example of supercritical channel flow. J. Atmos. Sci., 45, 3588-3605. doi: 10.1175/ 1520-0469(1988)045\%3C3588:TMLONC\%3E2.0.CO;2

Wyatt, L. R., L. J. Ledgard, and C. W. Anderson. 1997. Maximum-likelihood estimation of the directional distribution of $0.53-\mathrm{Hz}$ ocean waves. J. Atmos. Oceanic Technol., 14, 591-603. doi: 10.1175/1520-0426(1997)014\%3C0591:MLEOTD\%3E2.0.CO;2

Yang, W., and L. Di. 2004. An accurate and automated approach to georectification of HDF-EOS swath data. Photogramm. Eng. Remote Sens., 70(4), 397-404. doi: 10.14358/PERS.70.4.397

Zavala-Garay, J., J. Wilkin, and J. Levin. 2014. Data assimilation in coastal oceanography: IS4DVAR in the Regional Ocean Modeling System (ROMS), in Advanced Data Assimilation for Geosciences, E. Blayo, M. Bocquet, E. Cosme, and L. F. Cugliandolo, eds. Oxford: Oxford University Press, $555-576$.

Zhang, W. G., J. L. Wilkin, and H. G. Arango. 2010. Towards an integrated observation and modeling system in the New York Bight using variational methods. Part I: 4DVAR data assimilation. Ocean Modell., 35(3), 119-133. doi: 10.1016/j.ocemod.2010.08.003

Received: 10 November 2015; revised: 28 February 2017.

Editor's note: Contributions to The Sea: The Science of Ocean Prediction are being published separately in special issues of Journal of Marine Research and will be made available in a forthcoming supplement as Volume 17 of the series. 